\title{
Tools for User-Centred Design
}

\author{
Keith Case \\ Mechanical and Manufacturing Engineering \\ Loughborough University \\ Loughborough, Leicestershire, LE11 3TU, UK \\ K.Case@lboro.ac.uk
}

Keywords: User-centred design, ergonomics, inclusive design

\begin{abstract}
User-Centred Design aims to involve users at all stages of the design of products. Some of the basic principles are briefly considered together with their relationship to ergonomics. Tools for the application of User-Centred Design are discussed including specific tools such as digital human modelling, personas, manikin characters, inclusive design and human behavioural modelling.
\end{abstract}

\section{Introduction}

Donald Norman [1] is often credited with originating the term 'user-centred design' and he claims that it was the consequence of a period spent as an American in England trying to cope with (for an American) non-stereotypical light switches and (for everyone) the mystery of doors where there was no indication to the user if they had to be pushed, pulled or were sliding doors. The solutions he offered were based on three principles of not accepting the fault as a user if something does not work, use design principles (conceptual models, feedback, constraints, etc.) and use your powers of observation. These principles are expressing a need to involve the user in the design of products and not just in their use. In other words users should not be passive recipients of products that designers feel should be suitable for them. In the context of ergonomics Steve Pheasant [2] expressed this possible arrogance of the designer/ergonomist in the form of five 'fallacies':

- This design is satisfactory for me - it will therefore, be satisfactory for everybody else

- This design is satisfactory for the average person - it will therefore, be satisfactory for everybody else

- The variability of human beings is so great that it cannot possibly be catered for in any design - but since people are wonderfully adaptable it doesn't matter anyway

- Ergonomics is expensive and since products are actually purchased on appearance and styling, ergonomics considerations may conveniently be ignored

- Ergonomics is an excellent idea. I always design things with ergonomics in mind - but I do it intuitively and rely on my common sense so I don't need tables of data.

Hopefully professional ergonomists do not share a belief in these fallacies, but nevertheless they require not only an understanding of the issues of user-centred design and ergonomics but also some methodologies that help in the practical implementation of the concepts into design.

\section{Some Definitions}

Definitions of user-centred design abound but a typical expression from the field of HumanComputer Interaction (HCI) is 'the active involvement of users for a clear understanding of user and task requirements, iterative design and evaluation and a multi-disciplinary approach' [3].

Ergonomics (or human factors) is defined as 'the scientific discipline concerned with the understanding of interactions among humans and other elements of a system, and the profession that applies theory, principles, data and methods to design in order to optimize human well-being and overall system performance' [4]. 
Clearly ergonomics and human-centred design are at very least extremely closely related if not simply expressions of the same thing, and it would be difficult to find an ergonomist that did not subscribe to the principles of human-centred design.

\section{Basic Principles}

The difficulties in precisely defining user-centred design have led many to instead use a set of principles to guide the application of the methodology. Gulliksen et al [5], for example, provide twelve key principles that, although they were derived from the field of human-computer interaction, are also suitable for wider application. The principles (abbreviated here) are:

- User focus - the goals of the activity should guide the early development

- Active user involvement of representative users throughout the product lifecycle

- Evolutionary systems development - iterative and incremental product development

- Simple design representations - for ease of understanding by users and all stakeholders

- Prototyping - early and continuous prototyping in cooperation with end users

- Evaluate use in context - usability goals and design criteria to control development

- Explicit and conscious design activities - design directly related to user interface

- A professional attitude - use multidisciplinary teams

- Usability champion - usability experts should be involved throughout the design process

- Holistic design - all future use aspects to be developed in parallel

- Processes customization - adapt UCD to local conditions

- Establish a user-centred attitude - throughout the project team and client

The authors acknowledge that implementing such an approach from scratch within an organization will not be easy but that progressive movement towards it will result in improved designs.

There have similarly been many attempts to embed these principles in a design process to ensure their effective deployment. These would typically include (a) a user requirements analysis that would typically include user interviews and surveys, (b) conceptual design, (c) prototype/mock-ups to iteratively evaluate usability through focus groups, front-end concept evaluation and walkthroughs, (d) usability evaluation with the final design and finally (e) launch and maintenance including user manuals, training and customer feedback to improve future product updates.

\section{User-centred Design Tools and Techniques}

UCD tools and techniques include both general techniques for interacting directly with users and design tools which embody the concepts and principles of UCD. The former are dominated by techniques which arose out of human-computer interaction work and include task analysis, direct observation, activity diaries, questionnaires, interviews, group discussions and empathetic modelling [6]. An extensive review of tools is available from the website of the European Design for All e-Accessibility Network [7]. There has also been considerable work in the definition of standards for many aspects of human computer interfaces [8]. The latter, design tools embodying UCD concepts are the main focus of the rest of this paper with special attention given to our own research in the area.

\section{Digital Human Modelling}

The main tool used for design is Computer Aided Design (CAD) and so it is appropriate that for a human-centred approach there needs to be a model of the human to be used in conjunction with the CAD model of the product or system. These human models are generally known as Digital Human Models (DHM). SAMMIE (System for Aiding Man-Machine Interaction Evaluation) is a stand-alone system that has been used for many years in product and workplace design [9] and descriptions of JACK and RAMSIS applied in engineering product design can be found in 
Naumann and Rötting [10]. DHM meets some of the needs of UCD in terms of explicitly considering human variability (anthropometry, mobility, etc.), providing a virtual prototyping tool and potentially a simple way of presenting design ideas to users. Fig. 1 shows SAMMIE in use in the design and evaluation of train cabs [11].

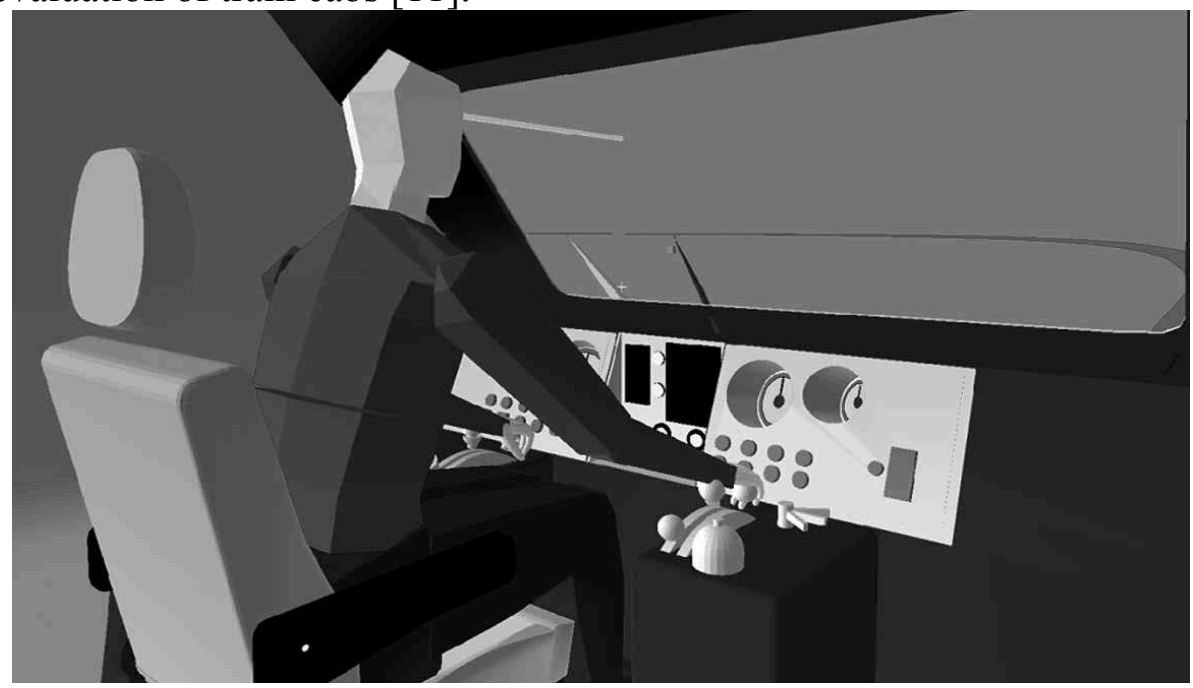

Figure 1. SAMMIE being used in the evaluation of a train cab for the Rail Safety and Standards Board [11]

\section{Personas}

Personas (also known as User Characters) [12] are used to encourage designers to actively consider the diversity of product users and their requirements, expectations and aspirations. Targeted users are represented by hypothetical characters that are used throughout the design process to convey real knowledge of real users in a way that creates empathy between designer and user. Between three and seven characters are frequently used and often pictures are used as illustrations (Fig. 2) [13].

Personas can be seen as parts of a transitional system where the characters support discussions within a product development team about user aspects. Even in cases where there has been direct interaction between project members and users, the characters can be a way to gain from, and store, real experiences and to support understanding and communication, e.g. with other project members who have not met users, and to evoke empathy for the users throughout the project.

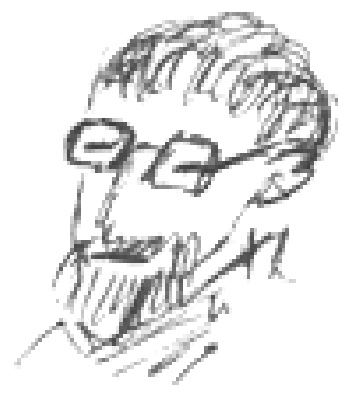

Bror is 45 years old and currently drives a Volvo with a manual gearbox. He appreciates basic cars and has the opinion that "new cars just cause trouble." Bror is not interested in having an automatic since that means higher fuel consumption, causes trouble and is unnecessary. His opinion is that a 'real' car is equipped with a manual gearbox and a clutch pedal. He does not care too much about performance. He has recently started to care somewhat about the environment and he thinks fuel efficiency is important but not crucial. A safe and secure car is more important than status $[14,15]$

Figure 2. An Example Character (Persona)

\section{Manikin Characters}

Digital Human Modelling (DHM) tools represent anthropometric and biomechanical characteristics, and connected aspects such as posture and comfort prediction. These are important aspects of design but clearly psychological and behavioural aspects of a user's interaction with products is equally important. The addition of these cognitive aspects within DHM [16] to create 
what might be called Virtual Humans is a daunting prospect. A more readily achievable approach would be to apply the user characters method to computer manikins, developing manikins into characters. This might be called Manikin Characters. In essence, such manikin characters could be the means to inform and inspire designers of many user related aspects. Unlike Virtual Humans, Manikin Characters would leave much of the design task with the designer, as the method supports the designer with appropriate information and stimulates creativity, rather than offering direct solutions. This may not be bad as a characteristic of designing is the creation of solutions to complex and ill-defined problems. All people, even designers, meet and interact with people, have opinions about people, recognise 'types' of people and are able to imagine how people might respond to certain situations and inputs.

The emotional responses of users to products is becoming a more important aspect of customer satisfaction [17], so designers will need to become involved with such issues, in conjunction with functionality and usability requirements. The manikin characters method is believed to assist in considering possible user responses and diversity, e.g. emotional responses, when generating and evaluating design proposals.

The validity of the ideas behind manikin characters is a challenging research question, as is how manikin characters might best be created, communicated to, and used by designers. One area to investigate would be how user characters should be linked to computer manikins, i.e. should the anthropometric models and character descriptions be separate features or associated, e.g. by mapping certain characters to certain manikins. A related issue would be manikin character family structure. The number of members in a manikin family to represent both anthropometric and personal diversity is unlikely to be the same. It would be convenient if it were, but there could be risks of sub-optimising if it was an objective to make the numbers match.

\section{Inclusive Design}

Inclusive Design (alternatively Design for All) is an approach that strongly considers the diverse needs of users. This could be related to any aspect of diversity but it is most frequently concerned with the design of mainstream products that meet the needs of and are attractive to older people and those with disabilities whilst also satisfying younger and able-bodied people. This again is totally in keeping with the concepts of UCD as the general population is increasingly older and (partially) as a consequence more likely to be disabled.

It is our view that Digital Human Modelling systems are extremely relevant in the context of inclusive design but are not ideally suited to the task. HADRIAN [11] is a DHM tool that has been built on SAMMIE and includes a database of 102 manikins based on real people, many of whom are older or have disabilities. Here there is a more direct and meaningful relationship between the DHM model and the real person when compared with the statistical aggregations found in conventional DHM system. Fig. 3 illustrates the approach in evaluating ticket machines for the London Docklands Light Railway [18].

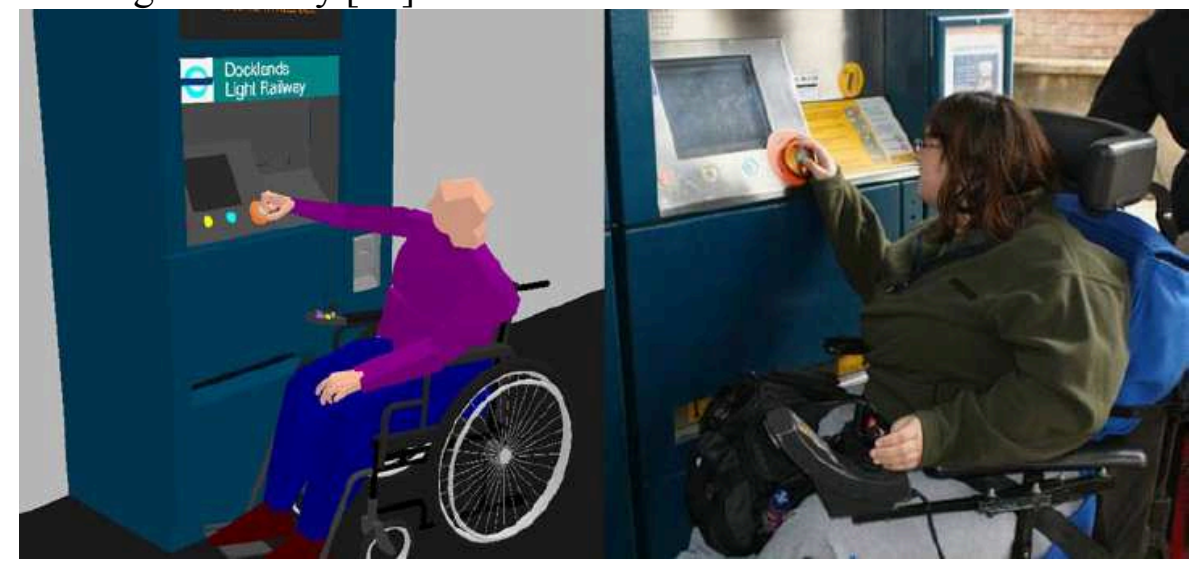

Figure 3. HADRIAN and real subject using Docklands Light Railway ticket machine [18] 


\section{Human Behaviour Modelling}

Humans are not simply a static collection of parameters such as their stature, range of motion at the elbow joint, etc but also show varying behavioural characteristics when interacting with their surroundings and other people. Our interest has been in adopting an inclusive design approach to modelling human behaviour in crowded public spaces such as multi-modal transport facilities (e.g. railway stations) This research was as part of the AUNT-SUE (Accessibility and User Needs in Transport for Sustainable Urban Environments) project and started with applying a video observational method to understand human movement and behaviour in crowded spaces in the real world. Six hours of video were analysed to produce almost 19,000 individual human movements and behaviours and six types of behavior (e.g. queuing) together with six influencing factors (e.g. personal space) were identified. Gaming software was used to simulate the human movement and behaviour in the virtual world and investigate facilities design, particularly with older people and those with disabilities in mind (Fig. 4)[19].
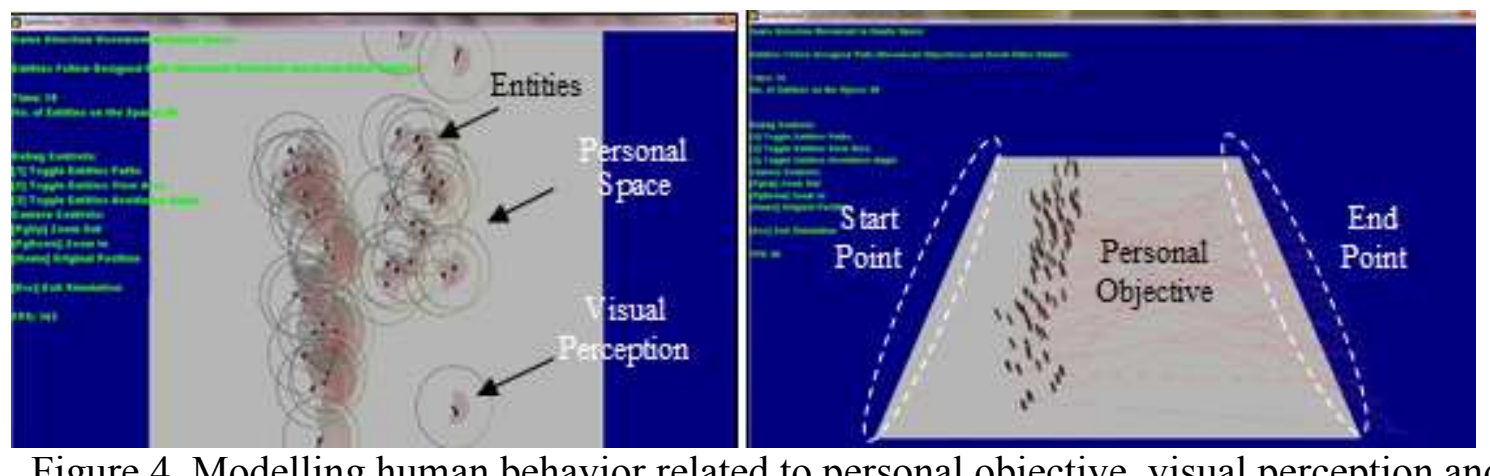

Figure 4. Modelling human behavior related to personal objective, visual perception and personal space [19]

\section{Conclusions}

User-centred design provides an extremely valuable framework within which it is possible to logically apply ergonomics design methods. However, it is not without its limitations and drawbacks [20]. It is often not practical to fully involve some users such as children and those with limited mental capacity. Beyond this, there are the issues that Webb [21] identified in that "users don't know what they need; users don't know what is good for them; users cannot properly articulate their needs, even when they do know them; users change their minds; users say different things to different people; users disagree with other users about what they need; users may not be real users at all". Perhaps we should accept that it is the professional ergonomist/designer to actively involve users in all stages of product design whilst being fully aware of the limitations of the method.

\section{References}

[1] D. A. Norman, The design of everyday things, Doubleday, New York, 1988.

[2] S. Pheasant, Bodyspace, Taylor \& Francis, London, 1986.

[3] K. Vredenburg, Y-M Mao, P. W. Smith and T. Carey, A survey of user-centered design practice, Proceedings of the SIGCHI Conference on Human Factors in Computing Systems, Minneapolis, Minnesota, USA, pp. 471-478, 2002.

[4] International Ergonomics Association, http://iea.cc, accessed 12 August 2013.

[5] J. Gulliksen, B. Göransson, I. Boivie, S. Blomkvist, J. Perrson and A. Cajander, Key principles for user-centred systems design, Behaviour and Information Technology, 22(6), pp397-409, 2010. 
[6] N. Colette, USERfit - Design-for-all methods and tools, in Human Aspects of Telecommunications for Disabled and Older People, COST 219bsi seminar, San Sebastian, Spain, pp.1-9, 1999.

[7] European Design for All e-Accessibility Network, http://www.education.edean.org/, accessed 12 August 2013.

[8] N. Bevan, International standards for HCI and usability, International Journal of HumanComputer Studies, 55, pp. 533-552, 2001.

[9] A. Hussain, K. Case, R. Marshall and S.J. Summerskill, An Inclusive Design Method for Addressing Human Variability and Work Performance Issues. International Journal of Engineering and Technology Innovation, 3(3), 144-155, 2013.

[10]A. Naumann and M. Rötting, Digital human modeling for design and evaluation of humanmachine systems, MMI-Interaktiv, ISSN 1439-7854, 2007.

[11]R. Marshall, K. Case, J. M. Porter, S. J. Summerskill, D. E. Gyi, P. Davis and R. E. Sims, HADRIAN: a virtual approach to design for all, Journal of Engineering Design, Vol 21, Nos. 2-3, pp. 253-273, 2010.

[12]L. Nielsen, From user to character - an investigation into user-descriptions in scenarios, DIS'02, Designing Interactive Systems, London, pp. 99-104, 2002.

[13]J. Pruitt, and J. Grudin, Personas: practice and theory. Conference on designing for user experiences, ACM Press, San Francisco, New York, pp. 1-15, 2003.

[14]D. Högberg, Ergonomics integration and user diversity in product design, Loughborough University. Doctoral Thesis, 2005.

[15]D. Högberg and K. Case, Manikin characters: User characters in human computer modelling. In P. D. Bust (Ed.), 'Contemporary Ergonomics 2006', the Proceedings of the Annual Conference of the Ergonomics Society (pp. 499-503). Robinson College, Cambridge, UK, 4-6 April 2006: London: Taylor \& Francis.

[16]P. Thorvald, K. Case and D. Högberg, D. Applying cognitive science to digital human modelling for user centred design. International Journal of Human Factors Modelling and Simulation, 3(1), pp. 90-106, 2012.

[17]T. van Gorp and E Adams, Design for Emotion, Elsevier, USA, 2012.

[18]R. Marshall, S. J. Summerskill, K. Case, G. E. Gyi and R. E. Sims, Development and evaluation of task based digital human modelling for inclusive design. In V. G. Duffy (Ed.), 'Advances in Applied Digital Human Modelling', the Proceedings of the Third International Conference on Applied Human Factors and Ergonomics, AHFE 2010 (pp. 129-138). Miami, Florida, USA, 2010.

[19]S. Mohamaddan and K. Case, Simulation of human movement and behaviour in crowded spaces using gaming software. Eleventh International Conference on Manufacturing Research, ICMR2013, Cranfield University, UK, 19-20 September 2013.

[20]P. Marti and L. J. Bannon, Exploring user-centred design in practice: Some caveats, Knowledge Technology and Policy, 22(1), pp.7-15, 2009.

[21]B. R. Webb, The role of users in interactive systems design: when computers are theatre, do we want the audience to write the script?, Behavious and Information Technology, 15 (2), pp. 76-83. 